LECTURES

ox

\section{THE PATHOLOGY AND TREATMENT OF DIABETES MELLITUS.}

BY

T. LAUDER BRUNTON, M.D., D.Sc.Edin., M.R.C.P.Lond., Lecturer on Materia Medica and Therapeutics, and Casualty Physician to St. Hartholomew's Hospital; ctc.

\section{LECTURE III.}

Having consic'sred the effect of increased formation of sugar, we must now look at the diminished combustion of it as a cause of diabetes.

The healthy organism is able to consume not only all the sugar produced within itself, but even more; and, if a solution of glucose or glycogen be injected in small quantities under the skin or even into the veins of an animal, no sugar will appear in the urine." This destruction of sugar probably goes on chiefly in the blood, lungs, and muscles, though it may take place in other tissues as well. Its occurrence in blood after it has been drawn is shown by the sugar contained in it disappearing after a short time when it is kept at a moderate temperature; and there is no reason to suppose that this does not go on within the body, more especially as Binzt and Zuntz have shown that the formation of acid, which goes hand in hand with the destruction of sugar, occurs even more quickly while the blood is still fluid, or, as we may say, alive, than after coagulation has taken place. The important part played by the lungs in the destructive process is evident from the great diminution which the sugar sometimes undergoes during its passage from the right side of the heart to the carotid artery; and the powers of muscle in this respect are shown by the observation of Ludwig and Genersich \pm , as well as of Bernard \$ु, that the blood which passes through the vessels of a contracting muscle contains much less sugar when it issues from the vein than when it enters the artery. And yet, strangely enough, Ludwig and Scheremetjewski\| found that, after grape-sugar had been injected into the veins of an animal, little or no increase took place in the oxygen consumed or the carbonic acid given off from the lungs-a result which indicates that grape-sugar, as such, is not burnt off in the body. On the other hand, however, they found that, when lactic acid as well as other organic acids, combined with soda, were injected into the veins, the amount both of oxygen and carbonic acid rose greatly, showing that these acids underwent combustion with great facility. Glycerine also undergoes combustion readily. Now, Bernard finds that, as the sugar disappears from blood, its place is taken by lactic acid $\uparrow$; and, as Du Bois.Reymond has shown, an accumulation of sarcolactic acid in muscles occurs after they have been kept in action.** Muscles after death acquire an acid reaction by the formation within them of lactic acid from sugar or glycogen which they containtt; and, when added to a solution of grape-sugar, they will cause the formation of acid in it also. That this conversion of sugar into lactic acid is due to a ferment, is shown by the close correspondence between it and other processes of fermentation $\neq \ddagger$. Thus, if the blood be heated so as to destroy the ferment, the sugar will remain unchanged $\$$; and Binz and his scholars have shown that quinine and other substances, which lessen fermentation, likewise diminish the production of acid in blood. Bernard has also demonstrated that blood, like other ferments, acts more rapidly on glucose than levulose; whereas alkalies, to which the destruction of the sugar in the blood was long attributed, act more rapidly on the latter kind of sugar than on the former.

The interesting experiments of Schultzen show more clearly than any others how sugar is decomposed in the body. A year or two ago, he found that, in animals poisoned by phosphorus, the processes of oxida. tion are arrested in the organism, but those of decomposition by fer. ments go on. \|\| In such animals, urea disappears fiom the urine, and

t Tieflenbach, op. cit.

+ Archiv für experimentelle Pathologic und Pharmacologic, vol. i, p. 20.

Ludwig's Arbeiten, 187r, p. 75

Leries, tome iv, p. xo2n.

8 Bernard, Reveiten, 1869 . pp. 144, and $14 \mathrm{r}^{\circ}$

Ludwigs Arciten, p. 1150

* Bernard, Kezme Scicntifique, 2ü Chemic, 1859, vol. Ixxvii, p. 233.

** Du Bois-Reymond, Fil Fernard, op. cit., p. 1159 .

t Some time ago I tried to separate this ferment from muscles by Von Wittich's method, by glycerine, but was only partially successful.

s Bernard, Lecons aut College de France, tome i, p. 230.

8 Bernard, Lecons au Ceber acute Phosphorvergiftutug, Separatabdruck aus den Arralen der Charití, Band $x$. is replaced by leucine and tyrosine, which, in the healthy organism, are converted into urea.* No sugar appears in the urine, but a kind of lactic acid is found in quantities exactly proportional to the amount of sugar afforded to the animals by their lood. This kind of lactic acid agrees exactly in its properties with the aldehyde of glycerine, and Schultzen considers the two bodies to be identical. $t$ He thinks that, in the normal condition, sugar is split up by the action of a ferment into this glycerin-aldehyde and glycerine in the manner indicated in the following formula: Glucose $\mathrm{C}^{6} \mathrm{H}^{12} \mathrm{O}^{6}+$ Hydrogen $\mathrm{H}^{2}=$ Glycerin. aldehyde $\mathrm{C}^{3} \mathrm{H}^{6} \mathrm{O}^{3}+$ Glycerine $\mathrm{C}^{3} \mathrm{H}^{8} \mathrm{O}^{3}$. When the ferment is absent, as he supposes it to be in some cases of diabetes, the sugar is not split up, and so does not undergo combustion, but is excreted in the urine. In diabetics, the processes of oxidation are not impeded; for the nitrogenous waste products appear in the urine as urea, and not as leucine, as they do when oxidation is impaired in phosphorus-poisoning. The imperfect combustion of the sugar is due, he considers, to the want of ferment which should prepare it for oxidation, and not to the want of oxygen.

In view of these facts, we are, I think, justified in believing that the sugar which is present in the blood becomes converted by the aid of a ferment in the blood, muscles, and probably lungs also, into lactic acid and glycerine; and then undergoes combustion, thus sustaining the temperature of the body. Supposing, however, that this ferment is deficient, a greater or less proportion of the sugar will not undergo conversion into acid, and will then remain unconsumed, as in Ludwig and Scheremetjewski's experiment. Unless the combustion of that quantity of sugar which does undergo transformation with the aid of fat, etc., be sufficient to sustain the temperature of the body, it will fall more or less below the normal; and this is actually what we find in a considerable number of diabetic patients. The muscular weakness which is observed in them is just what we would expect from the muscles being unable to make full use of the sugar which ought to supply them with energy for their work, though it is not improbable that excess of sugar in the blood may itself cause muscular fatigue. Whether this be the true explanation of their weakness or not, it is difficult to say ; for we do not yet know how it is that chemical action is transformed in muscle into mechanical work; nor are we acquainted with the manner in which oxygen is stored up during the hours of rest, in order to be expended during the time devoted to labour. Whenever we do learn this, we shall gain a deeper insight into diabetes; for Pet. tenkofer and Voit have found that patients aflicted with this disease have not the power which a healthy man possesses, of absorbing more oxygen during the night than they need at the time, and using it up during the day. They are thus obliged to work as it were from hand to mouth, and are incapable of any great exertion.

The formation of lactic acid depends on the sugar as well as the ferment, and it is quite possible that the former may be in fault as well as the latter. I have already mentioned that different specimens of glycogen are acted upon by ferments with varying degrees of facility; and it would seem to be the same with sugar even when ierived from similar sources, for Bernard, when arranging the different sorts according to the ease with which they are destroyed in the body, ranks sugar obtained from the liver above diabetic sugar. \$

The destruction of sugar probably goes on in the blood, brain, glands, etc., as well as in the muscles, but to a much less extent. In order that the sugar in the blood may be destroyed in the muscles, however, it must pass into them. Now, very little blood circulates through muscles when they are at rest, but the flow is much increased when they become active. More sugar will thus be carried to them and destroyed; but, as I have already mentioned, muscular exertion raises the blood-pressure, and increases the circulation in the liver and the formation of sugar in it, so that the balance is maintained. We can readily see that, if the liver go on producing sugar, and it be not destroyed in the muscles, it will accumulate in the blood, and at last appear in the urine. This, I believe, takes place in animals paralysed by woorara. Bernard thinks that the glycosuria produced by this poison, and also by large doses of morphia, is not due to their action on the muscles, but is to be ascribed entirely to their causing paralysis of the hepatic vaso-motor nerves and increased formation of sugar in the liver. I believe that woorara does exert this action; but the glycosuria is not due to it alone, but to its effects on the muscles also. My belief is founded on the experiments of Dock\|; and, to make the

- Schultzen und Nencki, Zcitschrift fii, Biologie, vol. viii, p. 124.

+ Schultzen, Berliver Klinische Wochenschrift, 1872, No. 35. p. 417.

t Ludwig and Scheremetjewski, op. cit., p. 145; Schultzen, op. cit.

8 It is possible that this may be due to the sugar from diabetic urine consistin sometimes of a mixture of sugar derived from the liver, and sugar absorbed from the intestine.

II Dock, Pflinger's Archiz', vol. v, p. 57 r. 
grounds of it more intelligible, I shall shortly give the results of his research. 1. When rabbits are starved, glycogen disappears from the liver. 2. In such rabbits, puncture of the fourth ventricle does not pro. duce diabetes. 3. After a few injections of cane-sugar into the sto. mach of starved rabbits, glycogen reappears in the liver. Injections of water, albumen, or fat, have not this effect. 4. If the fourth ventricle be punctured before the injection, no glycogen appears in the liver, and no sugar is found in the urine. 5. Poisoning by woorara produces dia. betes in starved rabbits, although puncture of the fourth ventricle does not. 6. After poisoning by woorara, injections of sugar into the stomach do not produce glycogen in the liver; but sugar is abundantly found in the urine.

I must also mention that Weiss* has discovered that a considerable amount of glycogen remains in the muscles of starved animals after it has completely disappeared from the liver; and they retain their muscular activity as long as it is present in the muscles. The explanation of these results is by no means difficult. Indeed, it would have been easy for any believer in Bernard's theory of the causation of diabetes by puncture of the fourth ventricle, to foretell that it would not. in. duce glycosuria in animals when their livers contained no glycogen; for, this being absent, no increase in the hepatic circulation could in. crease the formation of sugar. When the puncture is made, and the hepatic vessels are consequently dilated, before cane-sugar is in. jected into the stomach, no glycogen is found in the liver; for it is converted into sugar, and washed away by the blood as soon as it is formed. It does not appear in the urine, for it is used up by the muscles as quickly as it is absorbed from the intestines. When the animals are poisoned by woorara, there is no accumulation of glycogen in the liver, for the poison paralyses the bepatic vessels, and thus pro. duces the same effect as puncture; but it also prevents the muscles from using up the sugar, which therefore appears in the urine.

The occurrence of sugar in the urine of starved animals after woorarapoisoning must be due to the glyzogen in the muscles undergoing conversion into sugar, and its transformation being arrested at this stage, instead of changing into lactic acid and glycerine, and undergoing combustion as it ought to do.

There are some otber substances, such as nitrite of amylt and nitro. benzolf, which probably cause diabetes chiefiy by arresting the decom. position of sugar, although they may also act on the liver.

Since sugar has to be converted into lactic acid before it is burned off, and it is not improbable that the amount of this conversion is more or less regulated by the demand, we would not unnaturally expect that the injection of easily combustible organic acids into the blood, by preventing the combustion of sugar, might lead to its accumulation in the blood and its appearance in the urine. And such, in fact, is the case. According to Eckhard, $\S$ sugar appears in the urine of a rabbit after the introduction into its veins of carbonate, acetate, succinate, or valerianate of soda; and C. Goltz\| noticed it after putting lactic acid into the stomach of the same animal.

To recapitulate shortly what has already been said: The liver has two functions-I, that of taking up the sugar which it receives from the intestines, and converting it into glycogen; and 2, that of forming sugar again from glycogen. The muscles probably possess three functions. I. They take up sugar from the blood and convert it into glycogen. 2. They form sugar again from this glycogen. 3. They change both the sugar they form and the greatest part of that which they receive from the blood into lactic acid and gly. cerine, which undergo combustion. Diabetes may arise-I, from excessively rapid digestion of starch or sugar; 2 , from failure or im. perfection in the glycngenetic function of the liver, and possibly to some extent also of the muscles; 3 , from increased transformation of glycogen into sugar, due to accelerated circulation through the liver, or a larger proportion of ferment in the organ or the blood. The circulation may be quickened either by increase of the general arterial pressure or by dilatation of the vessels of the liver, and especially of the hepatic artery. Increased blood-pressure may be due to muscular exertion, such as occurs in epilepsy, or to contraction of the arterioles, such as is caused by impeded respiration, exposurc to cold, cholera, and Bright's disease. The hepatic vessels may be dilated reflexly by irritation applied to the vagus, either at its ends in the lungs, liver, or intestine, in its trunk, or at its roots in the medulla, or to the cerebrum, cerebellum, pons, and probably some of the sympathetic ganglia. They may also be dilated, and the cur-

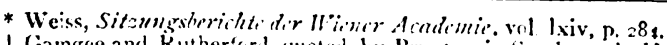

Gamece and kutherford, quoted by Brunton in Sanderomis llandlook for the Physion'dical Lal'eratory', p. 515; and Holfman, Reichert und Du Buis Reymond's Aritiz', 1872 , p. 746

1 Bwald, Contrallintt der. Medicinischen Wissenschaften. 1873, p. 819. $\$$ F.ckhard and Kulz. Pester medico-chiruergische P're'sse, Feb. $1873, \mathrm{p}$.

II G. Goltz, C'ntra!blatt fï. die .Mcticinischen Wissenchaftet, 1867, p. 705.
}

rent in them accelerated, by section of their vaso-motor nerves at any point between the medulla and the liver, provided that the intestinal vaso-motor nerves are not also divided, and the supply of blood so much diminished that no increase in the hepatic circulation follows the section. 4. Increased formation may also occur in the muscles from lessened combustion, due either $(a)$ to insufficiency of the ferment which should convert the sugar into lactic acid and glycerine, $(b)$ to an altered quality of the sugar which enables it to resist the action of the ferment, or (c) to diminished circulation through the muscles preventing the sugar from coming sufficiently into contact with the ferment.

Diagsosis. - We now come to the somewhat difficult task of trying to distinguish between the cases of diabetes depending on these dif. ferent causes; and this, I am afraid, I can very imperfectly perform. I have already mentioned that too rapid digestion of starch and imperfect glycogenesis in the liver would both give rise to glycosuria, occurring after meals, and arrested by abstinence from starch and sugar; but diminished combustion might lead to a somewhat similar result. In the latter case, however, the temperature would probably be below the normal, and in the former would not. The appearance of the patients, too, as Harley* points out, is very different. When the diabetes de. pends on diminished combustion, they are weak and emaciated, while in diabetes from increased formation of sugar, they are often ruddy and plump. Diabetes depending on increased transformation of glycogen in the liver will go on, even though an exclusively flesh-diet be em. ployed, and may thus be distinguished from diabetes depending on im. perfect glycogenesis. If it be due to increased transformation alone, and there be not at the same time diminished destruction of sugar, the temperature will not be below the normal. A temperature below the normal may be regarded as indicating that combustion of sugar is imperfect; but it by no means signifies that the disease is due to this cause alone, $t$ for at the same time there may be other conditions present which cause increased formation of sugar. Supposing that, the temperature being normal, we find that sugar continues to appear in the urine although the patient has been restricted to a diet of flesh alone, and we have thus determined that the diabetes is due to increased transformation in the liver, the next question is, On what does this depend? Is it due to increased blood. pressure, or to dilatation of the hepatic vessels? A general rise in the blood-pressure may be readily detected by the combined use of the stethoscope and sphygmograph. The tracing taken by the latter in. strument will show an oblique rise and slow descent of every pulse. wave. Such a tracing indicates high pressure, if the cardiac sounds be at the same time loud. A similar form may be obtained when the heart is feeble, although the blood.pressure is not above the normal; but the cardiac sounds will then be feeble also. If there be no rise in the general blood.pressure, we may suspect dilatation of the hepatic vessels; but it will be difficult to discover the cause of it. We must bear clearly in mind the various afferent and efferent nerves, irritation or paralysis of which may cause glycosuria, and localise the lesion as best we can by other symptoms which may point to one part or another. Thus, if we find glycosuria coming on in a phthisical patient, we may suspect irritation of the pulmonary branches of the vagus by the tubercle to be the exciting cause; while intestinal irritation or im. paired mental or motor functions will direct our attention to the abdo. minal branches of the vagus, or to the cerebrum and cerebellum. A history of ague will induce us to consider whether the source of irritation may not be in the nerves of the liver or spleen. One would expect that certain aneurisms of the subclavian artery, by stretching and paralysing the fibres forming the annulus of Vieussens, would cause glycosuria; but I am not aware of any cases of this sort.

TREATMENT. - The indications for treatment in diabetes are $I$, to lessen the production of sugar; and 2 , in cases where its combustion is imperfect, to aid its transformation, and to supply easily combustible materials, so as to sustain the temperature of the body and impart mus. cular strength.

The reason for lessening the production of sugar is that, when an excess of it is present in the blood, it causes dryness of the mouth, thirst, and discomfort, symptoms which disappear when its quantity is reduced. In order to effect this, all articles of food containing starch or sugar should be excluded from the patient's diet. Thus, no sugar at all will be formed in the intestine, any glycosuria depending on im. perfect glycogenesis will disappear, and the treatment will also constitute a means of diagnosis. At the same time, less glycogen will be formed in the liver, for a dict of meat does not afford nearly so much material for it as one containing starch or sugar. Thus glycusuria, de-

*. (ieorge Harley, The Urine and its Derangements, p. 240.

+ Rosenstein, Virchow's Archiv, xiii, 2858 ; and Harley, op. cit., second edi-
ion, p. 265 . 
pending on increased transformation of glycogen in the liver, will also be diminished.

The patient must be supplied with a diet consisting of nitrogenous food, such as butcher-meat, fish, eggs, and soups. Fat (which does not contribute in the least to the formation of sugar) may be given in all its forms, such as cream, butter, cheese, and oil. Spinach, lettuce, and cresses may be freely used, but celery and radishes only sparingly: while potatoes, carrots, parsnips, turnips, peas, French beans, cabbage, Brussels sprouts, cauliflower, brocoli, asparagus, seakale, and fruit of all kinds, both fresh and preserved, should be avoided, with the exception of nuts and almonds. Instead of bread, the patient should take either the gluten-bread supplied by Bonthron, I06, Regent Street, and Van Abbot, 5, Princes Street, Cavendish Square, or the bran- or almond-biscuit prepared by Blatchley, 362, Oxford Street.* Dr. W. Richardson strongly recommendst that the change from an ordinary to a restricted diet should be made very gradually, lest the patient become disgusted with his food. Rather than produce this injurious effect, it is better to relax the diet and permit him to eat sparingly of bread made of whole meal, or even of white bread toasted and potatoes. In the cases of diabetes which depends on imperfect glycogenesis, the restricted diet will be sufficient to prevent the appearance of sugar in the urine. Should it still continue notwithstanding the adoption of this regimen, the circulation in the liver must be reduced as much as possible. For this purpose, the blood-pressure should be reduced, and the blood should be drawn to the surface of the body by warm clothing and warm baths. The Turkish bath should be used occasionally. Bleeding is not likely to be employed now as a means of lowering the blood-pressure, but Lefèvre records a case in which diabetes was cured by its use conjointly with that of warm baths. $\ddagger$

It is very difficult to determine the point at which the irritation is situated on which reflex dilatation of the hepatic vessels may depend, and even if we could localise it, we might be unable to remove it. We therefore direct our attention rather to the nervous centres, through which the irritation is reflected to the liver; and, by lessening their excitability, we diminish its power over the hepatic vessels. The two remedies which are most serviceable for this purpose are opium and its alkaloid, codeia. Bromide of potassium and atropia, which might be expected to be useful, have been found of no service by Kretschy and Duchek $\S$. Half a grain of opium may be given three times a day to begin with, and the dose gradually increased il. Codeia, an excellent remedy, which we owe to Dr. Pavy, may be given in doses of a quarter to half a grain three times a day at first. My friend, Dr. Image, of Bury St. Edmunds, informs me that in one case he began with half a grain three times a day, and increased the dose by half a grain every four days, till the patient was taking five grains three times a day. The sugar then disappeared from the urine, but the treatment was continued for some time longer. About a year after, mental anxiety again brought on the disease, and five grains of codeia were at once given twice a day. This did not prevent the appearance of sugar in the urine, but it disappeared on the administration of five grains three times a day.

Excellent results have been obtained by Kratschmer from the use of morphia, the sugar disappearing completely from the urine, and the nutrition of the patient being greatly improved. $\uparrow$ Harley recommends conia or cannabis Indica, and has seen great benefit derived from a combination of conium, cannabis, and hydrocyanic acid.**

In certain cases, quinine proves extremely serviceable; and, whenever there is a history of exposure to malaria, it ought to be tried. Blumenthal $+\uparrow$ narrates a case of diabetes occurring in a man frequently

* An excellent diet-table from which this has been taken is contained in Pavy's urk on Diabetes, and edition, p. 263.

+ Richardson on Diabetes, p. 80.

Lef èvre, Magendie's Fournal, 1824 , p. 363

Kretschy, Wiener Me't. Wochenschr. I873, No. 3 and 4

1. I am not aware that the effect of opium in lessening the reflex dilatation of the hepatic vessels, which otherwise would occur when the central end of the vagus is stimulated, has ever been shown by direct experiment. Bernard has demonstrated the power of anasthetics, such as chloroform, to lessen reflex dilatation of the vessels of the salivary glands (Revue des Cours Scicntifiques, 1869, vi, page 383 ). Without being aware of his observations, I discovered, two years ago, that opium did solikewise. I was engaged in demonstrating to a class the functions of the various nerves connected with the submaxillary gland. The dog on which I was operating was deeply narcotised with opium; and, having exposed the nerves in presence of the class, I explained to them that, when I irritated the gustatory nerve by a galvanic current, the stimulus would be conveyed to the nerve-centre and cause reflex dilatation of the vessels of the gland, and a flow of saliva from its ducts. I then applied the irritation, but, to my surprise and disgust, not the slightest effect was produced. No change took place in the vessels, nor did the slightest trace of salıva issue from the duct. The opium had completely paralysed the nerve-centre, through which the effect was to be produced, and rendered the irritation fruitless.

I Kratschmer, Wien. Acad. Sitzungsbericht, $187^{2}$,

** George Harley, On the Urine, and edition, pp. 280 and $26 \mathrm{r}$

it Blumenthal, berliner Klin. Wochenschif if, 1873 , No. 13. troubled with migraine, and of a very nervous temperament. The sugar was s'ightly lessened by a meat ditt and the use of Carlsbad water, but the benerit was but slight, and the disease resisted codeia, arsenic, lactic acid, tannin, iron, and glycerine. Under the use of eleven and a half to thirty grains of quinine daily, the quantity of urine diminished; its specific gravity decreased; the thirst became less troublesome; the albumen, which had previously occasicnally appeared in small quantities, entirely disappeared; and the nervous affections rapidly improved.

Several years ago, Salkowsky* discovered that the livers of animals poisoned by arsenic contain no glycogen, and that it is impossible to produce diabetes in such animals either by puncture of the fourth ventricle or by curare. He therefore proposed arsenic as a remedy in diabetes. From this recommendation, Leubet gave it to the extent of one-third of a grain daily with good effect.

Devergie and Foville, junior, $\ddagger$ have also employed it with advan. tage. They were induced to do so by observing the diminution in the quantity of sugar which it produced in a case where it was administered for prurigo occurring in a diabetic patient. They begin with one drop of Fowler's solution twice a day, and gradually rise to twelve or fifteen drops, occasionally diminishing the dose, or stopping it altogether, as the symptoms seem to require.

Alkalies were proposed as a remedy for diabetes by Mialhe§ nearly thirty years ago, on the supposition that they would accelerate the decomposition and combustion of sugar in the organism. They frequently do prove very beneficial, but it is not certain that they increase the combustion of sugar. It is quite possible that they do so ; but, at any rate, the experiments of Lomikowsky\| seem to show that they lessen the production of sugar by diminishing the quantity, or preventirg the action, of the diastatic ferment by which glycogen is transformed into sugar. This author finds that, when bicarbonate of soda is given to dogs for some time, little or no sugar is found in their livers, even when they have lain for several hours after death. They contain glycogen, and therefore the absence of sugar must be due to want of ferment. Livers taken from other healthy dogs, which had got no alkalies, always contained much sugar when allowed to lie in the same way. Lomikowsky's conclusion is confirmed by the experiment of Pavy $\uparrow$, who found that the previous injection of carbonate of soda into the circulation prevented the appearance of sugar in the urine after removal of the superior cervical ganglion. A convenient way of giving alkalies is in the form of Vichy and Carlsbad waters. These seem to be more beneficial when the patient visits the springs than when he drinks them at home, probably because he is thus induced to take exercise, the use of which we shall presently see. The Vichy waters are purely alkaline, but the Carlsbad waters are purgative also, and are therefore to be preferred when any tendency to constipation exists. When the destruction of sugar is defective, we may endeavour both to increase it, and to supply easily combustible materials to the body in place of those products of the decomposition of sugar which normally serve as fuel to the organism.

Several months ago, I atternpted to increase the decomposition of sugar in diabetics by supplying the ferment which I supposed to be wanting. Since sugar is probably decomposed chiefly in the muscles, the ferment which splits it up is probably contained to a much greater extent in them than in any other part of the body. By giving the patients raw meat, we may hope that the ferment contained in it will be absorbed from the intestine into the blood, and there act on the sugar. It is necessary that the meat be given raw, for the heat to which meat is exposed in cooking completely destroys all ferments. The patients on whom I tried this plan of treatment were under the care of Drs. Black, Andrew, and Duckworth; and I take this opportunity of expressing my thanks to these gentlemen for the readiness with which they afforded me the means of making observations, and their kindness in supplying me with every facility, as well as to Messrs. Russell and Sawtell for the assistance they rendered me. The meat was finely chopped up in a sausage-machine, mixed with pepper and salt, and was either spread upon bread and butter, German fashion, or was made into a paste with bread and milk. Shortly after I began the treatment of one case, I learned from Dr. Duckworth that it had been tried empirically with complete success by the captain of a merchant vessel, who had prescribed for himself. In the cases treated in the hospital, however, no cure was effected, although in certain of them there was some temporary benefit. In order to increase the oxidation,

\footnotetext{
* Salkowsky, Centralblatt für die Medecin. Wissensch., 1865, D. 769.

+ Leube, Deutsch. Archiv fïr K'linische Medicin., i869, vol. v, p. 372.

$\$$ Gazette Médicale de Pal is, 1870, No. 22.

$\$$ Mialhe. Annales de Chemie, 1844, sér. iii, tome xii, p. гоo.

Lomikowsky, Berliner Klin. IVochensch., Oct. 6th, is73, p. 475.

II Lavy, On Diabites, and edition, p. 176
} 
iron may be administered; and I find a combination of perchloride of iron with hydrochlorate of morphia and spirit of chloroform very satisfactory.

As a great part of the sugar is probably broken up in the muscles by the action of a ferment, it is in the highest degree desirable that it should be brought as much as possible into contact with them. For this purpose, the circulation of the blood in which the sugar is contained must be increased as much as possible through the muscles, by making the patient take active exercise despite the languor of which he complains. Dr. William Richardson, ${ }^{*}$ who himself suffered from diabetes, says, in his excellent work on this disease: "Ten years ago, when I was first seized with an acute attack of diabetes, which threatened soon to end fatally, I became so weak, and had so little muscular power, that I could not walk a hundred yards without great fatigue. The muscles of my legs were so powerless, that I fell two or three times; and, in going down the slightest slope, I had to pay unusual attention to my legs, or I was sure to fall. I began to take exercise regularly two or three times a day; wet or fine, I took it. Gradually, I gained strength, so as to be able to walk five or six miles a day without fatigue. I now regularly walk from three to five or six miles a day." He also gives the case of a gentleman who derived but little benefit from a meat diet, Vichy water, iodide of potassium, or liquor arsenicalis, till he exchanged his sedentary life for active exercise, when his symptoms rapidly improved, and he soon recovered perfect health. The advice which Dr. Richardson gives regarding exercise seems to me to be so good, that I take the liberty of quoting it. "The exercise should be regularly sustained day by day, even in wet weather it should not be intermitted; of course, great care should be taken against wet feet, and the shoes or buots ought to be changed in wet weather on returning home; it should never be carried to real fatigue ; a feeling that exercise has been taken is the most that should be felt. To carry into effect regular and sustained daily exercise requires great moral courage anc energy, the languor and feeling of weakness are so great; but, if the exercise be only carried out patiently and perseveringly, the task will become not only more and more easy, but soon no longer a task, but positively a pleasure."

Easily combustible material may be supplied to the body in the shape of lactic acid, glycerine, cod-liver oil, cream, etc. As has already been shown, the two former are likely to be of little use in cases of diabetes depending on increased transformation, and not on diminished 'combustion; glycerine being even hurtful, and lactic acid able to induce the disease in animals.

Lactic acid may be administered in doses of from fifteen minims to a drachm; but, instead of giving it alone, I should prefer to give it in the form of lactate of soda, as a double benefit would be thus obtained. The organic acid, as we have already seen, is burnt off when combined with soda, and the salt is converted in the blood into a carbonate; and in this way we get the benefit which is often obtained by an alkaline treatment. The form in which I always recommend it, however, is that of buttermilk, as this quenches the thirst, supplies food, and also contains a ferment which, if absorbed, may be useful in aiding the conversion of sugar into lactic acid within the body. I am inclined to attribute the benefits occasionally derived from the use of skimmed milk to its possesing similar properties to buttermilk; but I consider the latter superior. When it is allowed to become very sour, and all its milksugar has been converted into lactic acid before it is used, it would probably be still better. I first heard of the use of sour buttermilk from an old woman in the country many years ago. She was loud in her praises of its efficacy in wasting diseases, and had striking cases to narrate by way of illustration. The manner of employing it which she recommended was to put the buttermilk into a large vessel, and add a fresh quantity every few days to replace what was drunk. The vessel was not to be washed out, so that a little of the old and sour milk always remained and quickened the formation of acid in each new addition. have never used it in this way; but, if I were living in the country, I should certainly give this plan a trial. I find that in London it is exceedingly difficult to obtain buttermilk at all.

Glycerine is strongly recommended by Schultzent as a substance which readily undergoes combustion in the body. He finds that, when a patient is placed on meat diet, the sugar disappears from the urine, and the thirst is no longer felt; but the nutrition remains indifferent. When glycerine is given at the same time, the muscular weakness diminishes, and the patient rapidly improves. He gives about half a fluidounce to a fluid-ounce and a quarter by measure (20 to 50 grammcs by weight) of glycerine, with about 80 grains $(5$ grammes) of tartaric or citric acid in rather less than four pints of water daily. The patient

* Richardison, ()n Diabetes, p. 9r.

* Schultzen, Ecrlincr Klinisch. Wochenschrift, $1 \varepsilon_{72}$, No. 35. drinks it from time to time instead of plain water. If the quantity of glycerine be increased to about an ounce and a half ( 60 gramines), there are sometimes nausea and diarrhœa. If the patient be not very thirsty, the glycerine may be given in one-half or one-quarter the quantity of water. If Schultzen's theory of the decomposition of sugar be correct, a combination of glycerine or lactic acid or some buttermilk along with a meat diet ought to yield very satisfactory results. Pavy found that glycerine increased the quantity of sugar passed by a patient, and made him thirsty. He gave it in doses of ten ounces a day, and the unsatisfactory result he obtained is probably due to the quantity being so large; for the glycerine, being more easily combustible than the sugar, appears to have prevented its decomposition, and thus allowed it to accumulate in the blood. This case of Pavy's indicates to us that, where diabetes depends on the formation of sugar being in. creased without its combustion being diminished, we need not expect to benefit our patients by supplying them with easily combustible foods, such as lactic acid and glycerine. We need, therefore, hardly try these remedies, except when the temperature of the body is low, as ascertained by the thermometer, or by the feelings of the patients, who complain of cold, and like to be constantly near the fire or covered with warm clothing.

\section{CLINICAL MEMORANDA.}

\section{CASE OF POISONING BY BERRIES OF THE MISTLETOE : RECOVERY.}

ON Wednesday, December 3 Ist, I873, at 9.30 1.Mr., I was called to see a boy, aged 14, who had been seized suddenly with alarming symptoms. The messenger (uncle of the patient), stated that, an hour previously to my being sent for, the boy had left the house apparently quite well ; but soon afterwards (about forty minutes), he was found lying in the street in a state of insensibility.

I saw the boy at 9.45 P.M., and, from his general appearance, the first impression produced on my mind was that he was in a state of intoxication (alcoholic). He was then reclining on some chairs, with his head rested on his mother's breast. His countenance was suffused, the lips livid, the conjunctiva injected, the pupils slightly dilated and fixed; the pulse was slow, full, and bounding; the temperature was normal; the breathing slow and stertorous. On pricking the soles of the feet, the limbs were quickly drawn up, showing there was no paralysis of the excito-motory functions. The odour of the breath gave no evidence of alcohol, in any form whatever.

Cold affusion was applied to the spine, by which means the patient was roused. He was now able to speak, but talked incoherently, had spectral illusions, and was inclined to be violent. At this stage he was incluced to take an emetic, consisting of ten grains of sulphate of zinc, dissolved in four ounces of water, which he was able to swallow without difficulty. Vomiting speedily followed this administration. On the ejected matters being examined, eight partly masticated berries of the mistletoe were found. The emesis was encouraged, and diiuents freely given.

The condition of the conjunctiva, together with the other symptoms, secmed to indicate considerable cerebral hyperæmia; I therefore ordered a sinapism to be applied to the nape of the neck. The patient was then put to bed. He continued in a state of excitement for two hours, after which he fell asleep. On the following morning (New Year's Day), at Io o'clock, I again visited him, when he declared himself well. He said he ate the berries at about 8.30 on the previous night (December 3Ist), soon after which he began to feel giddy, and from that time had no recollection of what had transpired. He assured me he had taken no spirit, wine, or beer, whatever. From the absence of any odour of spirit, either in the breath or vomited matters, and also from the fact of the presence of the berries in what was ejected, in addition to the boy stating that he commenced to be ill soon after eating the fruit of this plant, it seemed to me there can be no cloubt as to the nature of the case.

I have never read, nor heard, of a similar case, though I have no doubt such may have been, and perhaps are, of not unfrequent occurrence. The symptoms presented by this boy, then, seemed to have been due alone to the action of this parasitic plant.

JoSEPH Dixon, L.R.C.P.Ed., etc., Whitehaven. 